\title{
Editorial: The February 2022 cover paper
}

\author{
C. Barry Carter $^{1, *}$ (D) \\ ${ }^{1}$ Department of Chemical and Biomolecular Engineering, University of Connecticut, Storrs, CT 06239, USA
}

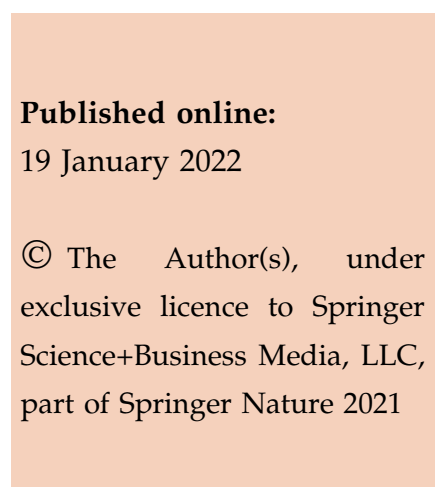

The cover for the February 2022 issues of the Journal of Materials Science shows a selection of images and plots from the paper by Schönmaier et al. [1], which appeared in the December 2021 issue. The paper was handled by our Editor Philip Nash; Philip is incidentally the longest serving current editor. It was included in a Topical Collection with other papers on "Metals \& Corrosion." The paper describes a collaboration between researchers in Germany and Austria. The topic concerns how heat treatment affects the microstructure and mechanical properties of creepresistant steel weld metal. The research uses a combination of scanning electron microscopy (SEM), scanning transmission electron microscopy (STEM, electron backscatter diffraction (EBSD) and transmission Kikuchi diffraction (TKD) combined with hardness maps and some nice schematics of dislocations! What more could one ask?

As of December 26, 2021, it has been accessed 1200 times which is quite exceptional. It may never become the most highly cited paper, but it will remain heavily downloaded. We have had similar papers previously what were heavily downloaded by engineers working in industry who were not necessarily writing papers! At the Journal of Materials Science, we regard this as a great success: Such papers have a real impact.

As was the case for January's cover, this month's choice illustrates the importance of multidisciplinary materials research: The structure and chemistry of the region surrounding the weld must be well characterized, and then, the properties of the joining material and its behavior during processing can be understood. As was the case for January's cover, the paper is a nice example of the Tetrahedron of Materials Science (processing, structure, properties and performance). Welding may not be the most glamorous topic in science, but as the American Welding Society (www.AWS.org) points out, welding is a driving force for the economy (and not just in the car industry).

The paper is 16 published pages long, which is a page or two longer than the average for JMS (we do favor full archival papers). As is the case for all

Address correspondence to E-mail: cbcarter@gmail.com 
papers published in JMS (OA or not) it has color throughout-in both the hard copy and the pdf. This paper was published Open Access, but it does also have a SharedIt link like all articles in JMS (https:/ / rdcu.be/cDSxB); all papers published in JMS are free to read using the SharedIt link from the moment they appear online.

\section{Reference}

[1] Schönmaier H, Fleißner-Rieger C, Krein R, Schmitz-Niederau M, Schnitzer R (2021) On the impact of post weld heat treatment on the microstructure and mechanical properties of creep resistant $2.25 \mathrm{Cr}-1 \mathrm{Mo}-0.25 \mathrm{~V}$ weld metal. J Mater Sci 56:20208-20223. https://doi.org/10.1007/s10853-021-066182

Publisher's Note Springer Nature remains neutral with regard to jurisdictional claims in published maps and institutional affiliations. 